\title{
THE LONGEVITY OF SUSTAINABLE VINEYARD PRACTICES1
}

Jean Dodson Peterson, Forrest Richmond, Adrienne Ferrara, Katharine Watts, and L. Federico Casassa, California Polytechnic State University, United States

\begin{abstract}
Toelle Ainsley, vineyard manager at ARCH Vineyards, stood on the edge of Block 001. Block 001 was a vineyard that overlooked the northern tip of the Edna Valley American Viticultural Area (AVA), located in California's Central Coast. It was a beautiful morning in spring of 2018 just before budbreak and the beginning of the new growing season. This area of California's Central Coast was known for producing delicate Pinot Noir, perfumed Syrah, and supple Chardonnay wines.1 Joelle thought Block 001was one of the best representations of the potential Pinot Noir had in this area of the world. Although the fruit from this block was consistently of premium quality, this vineyard had become particularly challenging over the past several years. Block 001 was transitioning from conventional farming practices to sustainable methods, which included the minimization of synthetic chemicals and fertilizers in addition to the implementation of lower water use cover crops. The transition led to higher management costs, which, unfortunately, had not improved grapevine developmental traits (yield/pruning weight ratios, canopy structure) or enhanced wine quality (sensory characteristics, anthocyanins).
\end{abstract}

ARCH asked Joelle to make a recommendation about whether the block should continue to be managed using environmentally sustainable techniques or return to the conventional management practices it had once been under. Joelle knew that the winery had no desire to increase bottle price in the near future, so any increased cost associated with farming would have to continually be absorbed. Pressures from the winery and from wine consumers pulled her in two different directions. As badly as she hoped to see immediate improvement in vine developmental traits and wine quality, she knew that farming sustainably to encourage healthy soil microbes could take decades to improve vine health and fruit. As with any major business

1 At the request of the winery owner, the identities of the winery, vineyard management company, and all associated employees have been disguised. 
investment, the decision to move toward more environmentally sensitive farming practices extended beyond the scope of the farm. The move toward more progressive farming through Sustainability in Practice (SIP) Certification 2 and more focused environmental practices provided ARCH with talking points with its customers. Joelle wondered: Could she coordinate her efforts with ARCH's marketing team and SIP to promote their sustainable farming strategy to enhance sales and increase the goodwill and trust with customers? Could doing so support a necessary price increase?

Despite all her efforts to implement the most cutting-edge, environmentally sensitive techniques at $\mathrm{ARCH}$, Joelle remained unsure if future consumer demand for sustainably produced wines would be sufficient to compensate for the lack of increased vine health and wine quality. Joelle needed to decide how to balance the desire to farm sustainably with the increased farming costs. As she stood overlooking the vineyard she knew so well, Joelle thought, "How do I properly decide to balance my desire to be sustainable and the market demand with the expenses related to farming a vineyard sustainably? Is sustainable viticulture truly sustainable?"

\section{SUSTAINABILITY AND WINE MARKETING IN THE U.S.}

The wine market was extremely competitive, consisting of 4,425 wineries in California and 9,762 in North America in 2017.3 By 2018, the number of U.S. wine producers exceeded that of all alcoholic beverage producers as well as most categories of consumer-packaged goods. Customers became more discerning about selecting consumable products from safe and trustworthy producers. Additionally, the industry had been evolving rapidly to embrace more environmentally friendly vineyard practices and consumers placed a higher value on wines produced by sustainable means. 4 To put that in perspective, a 2014 survey found that 77 percent of Americans considered sustainability when making purchases.5

Sales in the wine industry were divided into two major categories: wholesale and direct to consumer (DTC). While wholesale functioned in a number of ways, the industry primarily operated in the three-tier system. This system was part of the agreement to repeal Prohibition and meant that a winery (tier one) would appoint a distributor (tier two) in a given market. That distributor represented the wine brand through a sales team that sold to stores and restaurants (tier three) in that market. A winery had many customers in this model, each requiring a level of dedicated marketing. Major distributors carried thousands of wines in their portfolio, which often segmented wines into categories. These categories served to help sales teams more efficiently sort through brands and varietals to find a better fit with a particular wine account. For example, if a hotel customer was looking for half bottles, the distributor catalog could have a specific list of $375 \mathrm{ml}$ formats as opposed to the regular-sized $750 \mathrm{ml}$ wine bottle. If the sales representative 
compiled such a list of alternative format wines to submit to the hotel food and beverage buyer, then it became much simpler to make the sale.

With the end of a major recession in 2010, consumer spending on wines rebounded. The industry witnessed a growing demand from consumers for more sustainable wines and, in turn, more requests for those wines from wine buyers. Distributors were developing lists of wines in their portfolios that fit this sustainable category. In San Francisco, there was a growing list of wine accounts whose buyers exclusively purchased and served sustainably made wines. Ruby Wine, a natural wine bar and shop located in the city's Potrero Hill district, served only wines with a “deeply minimal style." Other San Francisco wine bars and restaurants, like Terroir and High Treason, also belonged to this growing list of sustainably focused buyers. Alternatively, a wine broker for the cruise ship industry was asked if cruise lines have interest in sustainably farmed wines. The broker replied, "Yes, but they don't want to pay extra for it." In the 2018-2019 season, Princess Cruises and Holland America Line printed their on-ship wine lists with a special icon indicating organic and sustainable wine options. Much like food menus indicating hearthealthy or vegan options, wine specialty merchants, restaurants, hotels, and cruise ships began to provide better information to aid in consumer decision making, at least when it came to wines.

Direct to consumer was an area of the wine business experiencing significant growth. In 2017, ShipCompliant, which makes compliance software for the wine industry, noted that wine shipments DTC rose 15.3 percent. Direct-to-consumer wineries typically featured tasting rooms, mailing lists of customers, wine clubs, consumer events, social media promotions, and customer relationship management. These activities enabled wineries to interact with customers in order to sell wine directly to them. There was, however, an inverse relationship between the size of a winery and the percentage sales dedicated to DTC. For wineries that produced 25,000 cases or less, DTC tended to represent the majority of winery sales. For wineries producing between 100,000 and 249,999 cases, DTC dropped to less than 20 percent. For wineries 250,000 cases or more, it was less than 10 percent.6

In April 2018, the Wine Market Council released the results of their research of consumer habits titled, "Green Wine Study: U.S. Wine Consumer Attitudes Toward Organic, Sustainable, and Biodynamic Production." This study of high-frequency wine consumers suggested a willingness of consumers to pay a slight premium for wines in this category.7

However, communicating sustainability to wine drinkers remained challenging. In the March 2010 article, "Eco-Labeling Strategies and Price-Premium," authors Magali A. Delmas and Laura E. Grant discussed what they called "the pitfalls of eco-labeling" writing:

Green products are credence goods; consumers cannot ascertain their environmental qualities during purchase or use. Customers are not present during the production process 
of the product and therefore cannot observe environmental friendliness of production. The objective of eco-labels is to reduce information asymmetry between the producer of green products and consumers by providing credible information related to the environmental attributes of the product and to signal that the product is superior in this regard to a nonlabelled product (Crespi \& Marette, 2005). The implicit goal of eco-labels is to prompt informed purchasing choices by environmentally responsible consumers (Leire \& Thidell, 2005, p. 1062).

Wine-grape growers and wine companies that wish to convey a message of sustainable farming to their customers should first consider what consumers understand to be sustainable practices and then determine how they will communicate it through a particular sales channel.

The wine industry traditionally was deeply entrenched in buzz-word marketing. Terms like goldmedal winning, family owned, food friendly, and handcrafted adorn wine merchandising. As observed from the rise in popularity of farm-to-table restaurants, a popular marketing term could also result in consumer confusion over what that term actually meant. If there was a lack of clarity around the term, would this cause confusion among buyers? Organic, sustainable, green, natural, biodynamic, native, and natural were all terms applied to marketing campaigns with little explanation about the practices rooted in long-term environmental farming. Did the consumer know the difference and were they willing to pay for it? ARCH would need to dovetail efforts in environmentally progressive farming with their marketing and sales in a way that was both beneficial to sales and understood by customers. In an article written after meeting with Joelle, Esther Mobley of the San Francisco Chronicle wrote in June 2018:

As long as the field continues to crowd with competing acronyms, filling wine bottles' back labels with small, largely indistinguishable stamps of approval, it's hard to know how effectively anyone is getting the message. And until consumers get that message, and respond by changing their spending habits, the incentive for wineries and vineyards to go green — and to prove it with a certification — will remain based on good faith. It ought instead to be based on good business. 8

\section{THE SUSTAINABILITY MOVEMENT IN THE U.S. VITICULTURE INDUSTRY}

The ideology of sustainability in agriculture revolved around respecting the environment, considering the safety and well-being of employees, and, in some circles of thought, maintaining sound business practices. Considering the extensive history wine-grape growing had in California, the recognition and implementation of sustainable practices were relatively new, especially to California's Central Coast. Prior to the late 1980s, Central Coast farmers focused primarily on crops such as barley or wheat, but from the early 1990s to the early 2000s, winegrape acreage rose from around 6,600 acres to close to 19,000 acres in San Luis Obispo County, in accordance with the general trend observed for California wine-grape acreage in that same 
period (Exhibit 1). Without formal education in viticulture, many newly converted farmers began looking for guidance related to proper vineyard practices. In response to this demand, the Vineyard Team formed in 1994 as a non-profit grower group designed to provide education and move the viticulture industry toward sustainable practices.9 This industry group was novel, not just for the Central Coast, but for the viticulture industry as a whole. No other grower group focused primarily on sustainability or had membership across so many AVAs. Sustainability was certainly not a hot topic at the time and true (not modernized) conventional practices were generally better understood. As a result, the founding members of the Vineyard Team saw an opportunity to provide some much-needed assistance to the relatively young and up-and-coming wine region.

In 1996, Kris Beal, the executive director of the Vineyard Team, helped design the first method to assess the levels of sustainability in a vineyard. It was termed the Positive Point System (PPS) and was a self-assessment that considered factors such as integrated pest management (IPM), soil management techniques, and irrigation regimens.10 By 2002, the Vineyard Team and growers shifted to a third-party certification process that would be "meaningful, measurable, and verifiable." This program was SIP. Sustainability in Practice regulations were considered more stringent than the United States Department of Agriculture's (USDA) organic certification requirements because SIP considered resources above and beyond prohibiting synthetic pesticides and fertilizers.11 Kris believed SIP Certification was vital to the longevity of the winegrape growing region because:

There is an increased understanding of potential impact growers are having on things beyond the fence line. Sustainability in Practice evokes global understanding and level of responsibility from industry, as they are required to consider and document the impact of vineyard inputs on factors such as habitat and biodiversity, water quality, as well as water and energy conservation. 12 


\section{Exhibit 1}

\section{Evolution of California Bearing and Non-Bearing Wine Grape Acreage from 1970-2017}

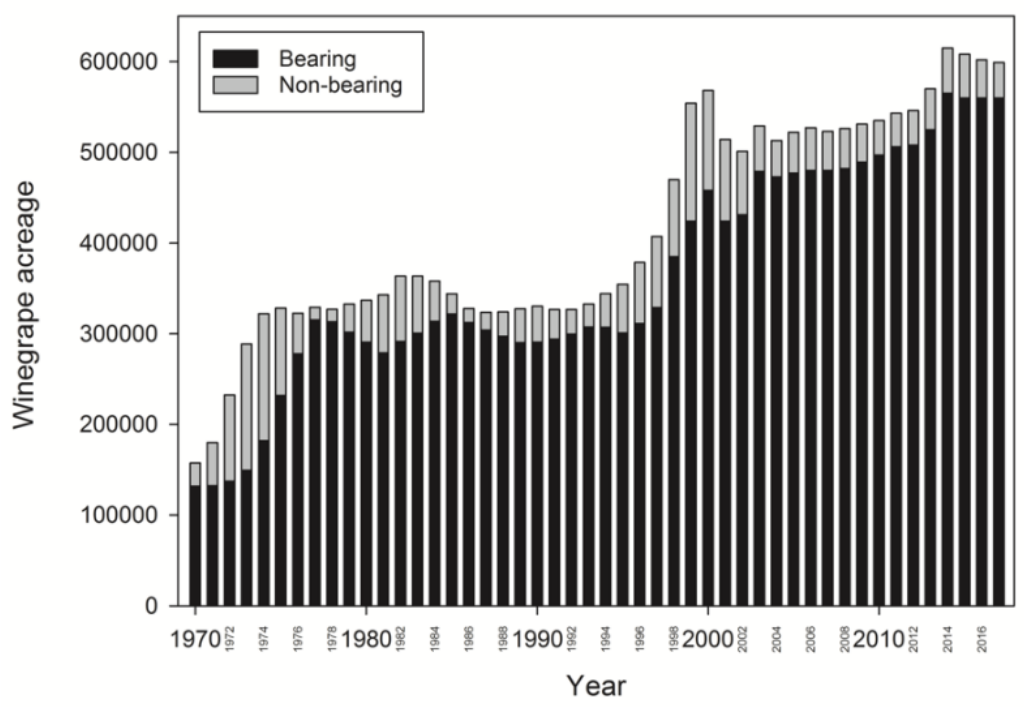

Source: USDA (2018) National Agricultural Statistics Service California Field Office. Available Online: https://www.nass.usda.gov/Statistics_by_State/California/Publications/Specialty_and_Other_Releases/Grapes/Acrea ge/Reports/index.php

By the end of 2017, Kris and the SIP program certified 85 growers, 268 vineyards, and 36,700 acres in the Central Coast (Exhibit 2). The number of participants had steadily increased by 17 percent on average every year since 2008 .

According to Kris, consumers had already begun identifying SIP certified growers and wineries, by examining the SIP designation labels on bottles. Although it was unclear how much consumer recognition and value were placed on additional designations such as SIP, it was thought to be favorably viewed. Unfortunately, translating it to dollars was difficult for producers such as ARCH. 


\section{Exhibit 2}

\section{Central Coast SIP Certified Acres, Vineyards, and Growers from 2008-2017}

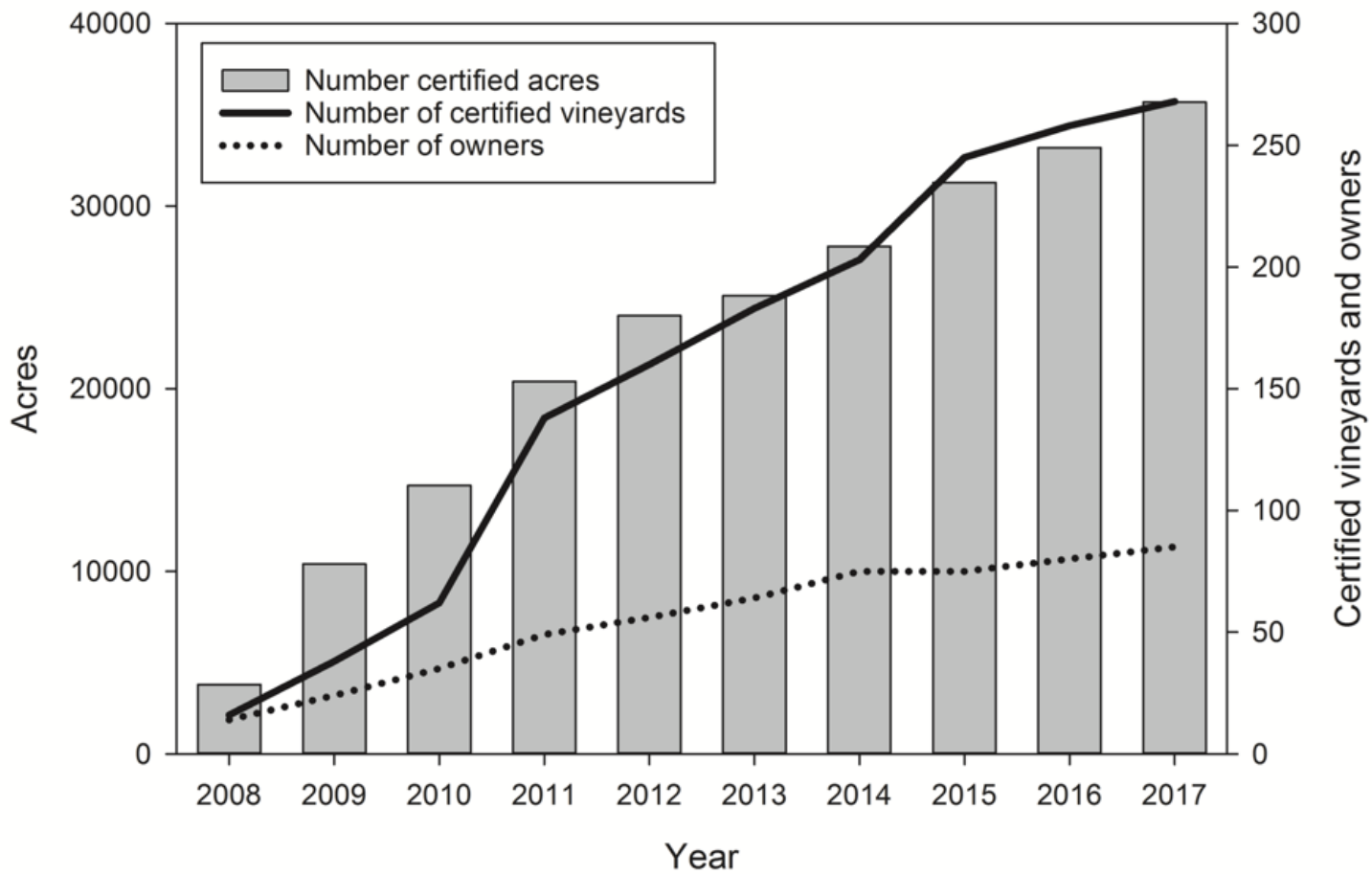

Source: Sustainability in Practice Program Director, 2018.

\section{JOELLE'S BACKGROUND}

Joelle grew up in an agricultural region and learned the modem farming methods to prepare her for her current position. She grew up in Crow's Landing, located in California's Central Valley, where her grandfather and father had a commercial spray company that aimed to control fungal and pest pressures in orchard production. For more than 30 successful years, her father and grandfather depended on conventional farming practices and spray programs for their livelihood. When Joelle was only 12-years old, she slept in the truck overnight so that she could be ready to assist her father as they monitored conditions in several different orchards simultaneously. She often reflected on this experience saying, "Everything was very traditional (conventional) back then. We were spraying things that were widely accepted at the time as industry standard, but now are not even kosher to talk about publicly. We weren't worried about it. It was our life; it was our everything."

Over the years technologies and chemicals improved and changed and, with it, so did Joelle. She used strategic leaf pulling in the canopy to increase air movement in the fruiting zone and cut back on her need to apply high levels of fungicides. She incorporated the use of low water 
demand cover crops to save soil water reserves while still contributing to soil organic matter. Joelle was also on the forefront of implementing new, safer chemical controls or tilling as a means of weed control. Over the course of her career, she was exposed to various agricultural practices, some of which would be considered precursors to the sustainability movement the wine industry has embraced today. One such experience that helped to shape her approach to viticulture was with the California Agriculture Leadership program (Class '46), which was a program designed to create transformational learning experiences and leadership training for college students in California. As a result of her time with the organization, she adopted the motto:

Sustainability is a whole vineyard or farm approach, an effort to keep it viable. I don't worry about the consumer; I worry about the land. I answer to the land. I am responsible for leaving the land in the same or better condition than when I received it. To achieve that goal, I must consider the entire biodiversity and ecosystem of my vineyard.13

Earlier in her career as the pest control advisor and assistant vineyard manager for Horizon Vineyard Management, a management company subsequently hired by ARCH, Joelle tried to define what environmentally sensitive practices meant. She worked tirelessly to put those ideals into practice.14 Joelle was promoted to vineyard manager at ARCH in early 2017. Logistics and assessment of the financial viability of sustainable practices (such as increased labor costs and more expensive approaches to address vineyard issues) now became her responsibility. She was forced to see sustainability through a new lens; a lens that was suddenly heavily focused on budgeting, organization, and personnel management. This new role forced her to do a deeper evaluation of the logistics and longevity of farming in a sustainable manner.

\section{CONVERSION TO SUSTAINABLE FARMING}

With the evolution of farming techniques in the Central Coast, ARCH switched to cultivation in place of herbicide applications and opted to use organic fertilizer over synthetic applications in most of Block 001. During this transition period, Joelle and the ARCH team closely monitored the costs involved in making the move to sustainability.

For instance, Joelle tracked the cost to control weeds, comparing the manual method of using the Clemens weed knife to that of herbicide applications (Exhibit 3). At a comparative number of acres farmed, the Clemens method proved much more labor intensive than the conventional herbicide program. Labor hours and labor costs were 12-fold higher and supervision costs were on average 210 percent higher under the Clemens method. After including the cost of materials associated with the conventional herbicide program, the team calculated that the overall cost per acre was 101 percent higher under the Clemens method. This number was significant considering $\mathrm{ARCH}$ had no desire to increase bottle price in the near future. 


\section{Exhibit 3}

\section{Weed Control Costs: Conventional (Herbicide) Versus Sustainable (Clemens Weed Knife)}

\begin{tabular}{ccccccccc}
\hline \hline $\begin{array}{c}\text { Cultivation } \\
\text { Program }\end{array}$ & Acres & $\begin{array}{c}\text { Average } \\
\text { number of } \\
\text { passes }\end{array}$ & $\begin{array}{c}\text { Labor } \\
\text { hours }\end{array}$ & $\begin{array}{c}\text { Labor } \\
\text { costs }^{1}\end{array}$ & $\begin{array}{c}\text { Supervision } \\
\text { costs }\end{array}$ & $\begin{array}{c}\text { Labor } \\
\text { (cost/acre) }\end{array}$ & $\begin{array}{c}\text { Materials } \\
\text { (cost/acre) }\end{array}$ & $\begin{array}{c}\text { Overall } \\
\text { cost/acre }\end{array}$ \\
\hline Clemens & 219.7 & 12.2 & $1,907.4$ & $\$ 24,957.2$ & $\$ 1,449.9$ & $\$ 332.60$ & $\$ 0.00$ & $\$ 332.60$ \\
Herbicide & 202.6 & 5 & 153.2 & $\$ 2,178.5$ & $\$ 467.9$ & $\$ 31.10$ & $\$ 134.54$ & $\$ 165.60$ \\
\hline \hline
\end{tabular}

Source: Horizon Vineyard Management Cost Comparison (2017).

1Labor costs include operation of the tractor, cutting and removing weeds, and hoeing.

As a result of the conversion to more sustainable practices in Block 001, the labor costs increased. To maintain the vineyard, it required more vineyard passes with the vineyard crew and more tractor work. Additionally, the potential risk of soil compaction in the inner rows and increases in greenhouse gas emissions from repeated tractor use alarmed Joelle. To try to quantify their efforts, the ARCH team initiated work with a research team at California State University to quantify changes in soil health and wine quality to help them justify the transition to more environmentally friendly, albeit sometimes more expensive, practices (See Appendix for details on the compiled vineyard data). After three years of implementing this new approach, wine quality, measured via specific chemical analyses (phenolic composition, wine color, wine basic chemistry) and sensory analysis (conducted with trained wine tasters), had not increased, but populations of soil microbes became more diverse and abundant than ever before when compared to the more conventionally farmed sections of the vineyard block.

Miles Owens, the in-house director of viticulture for $\mathrm{ARCH}$, originated the transition to and subsequent quantification of sustainable practices in Block 001. 15 He was pleased with the positive changes documented in the soil profile. Despite his enthusiasm with the improvement in soil health, he was certainly disappointed that there was not any observable increase in the quality of the fruit. For the past three years, Block 001 inputs had done nothing but increase with intensified labor, research, and transitory costs. This continued increase in cost, especially those associated with additional labor, was a real concern. Miles wondered if the consumer would appreciate the efforts and would be able to recognize the time and energy invested in the block and the environment. Both he and Joelle realized that it could take decades for the soil changes to translate to increased vine and fruit health and subsequent wine quality, but they both felt driven to make sustainability part of common practice in their daily decisions. Joelle knew Miles and the winery team wanted to minimize farming costs since consumer spending was forecasted to slacken in 2019 due to marketplace saturation. Miles wanted to help position his company to be as competitive in the marketplace as possible and do so as financially responsible as possible. 
Joelle wondered if the increased costs to farm sustainably could be effectively offset by consumer interest and willingness to pay for a sustainable product. She questioned how her winery would react to the increased management costs if the wine quality continued to show no change, especially if they were not interested in increasing the bottle price. Could ARCH continue to comfortably absorb the cost to maintain SIP Certification, and, perhaps more importantly, was there enough consumer recognition of the SIP label to matter? 16 Would the adherence to SIP practices attract new consumers and offset any increase in management cost?

Making a personal connection with their clientele through their tasting room and hospitality businesses was an imperative selling strategy at Arch. Because the winery partnerships for ARCH fell between 10,000 and 50,000 cases, it was significant to have a healthy direct sales channel. The 2018 Silicon Valley Bank Report noted that wineries that produced 10,000 to 24,999 cases annually had direct sales exceeding 65 percent of their total sales volume. At 25,000 to 49,999 cases, direct sales fell approximately 44 percent, but remained a significant influence on total sales volume.17

The focused effort in environmentally sensitive farming was reflected in the consumer's experience in its tasting room. Block 001 was across the street from the tasting room and provided the backdrop to the tasting experience. As customers tasted wine, they were influenced by the view of the sustainable vineyard. Additionally, staff education regarding the new sustainable farming practices provided fresh talking points to showcase with tasters.

Joelle knew that consumers often did not understand the difference among conventional, organic, and sustainable farming. Consumer confusion about "sustainable wine" was compounded by the absence of a common or legal definition of what that meant. She struggled to define sustainable viticulture. One example of her concern related to the common vineyard practice of mulching. The sustainable practice of mulching the prunings at the end of a season to improve carbon and nitrogen ratios was thought to increase the risk of leaving fungal inoculum in the vineyard, which could result in higher fungal pressure and a decrease in vine health and fruit quality. The results of fungal inoculum exposure could also require more work in the vineyard, such as additional fungicide applications. Mitigating fungal concerns would also add more passes through the vineyard and counterbalance the intention to minimize interventions.

\section{EVOLUTION OF BLOCK 001}

The history of Block 001's evolution toward sustainability began with Lawrence Larsen. Lawrence, general manager for Horizon Vineyard Management, had been farming a long time. From the late 1970s through 1995, Lawrence farmed table grapes in the San Joaquin Valley, where he learned an incredible amount about managing the environment and the ecosystem 
around him. From this experience he embraced the idea that the worker must come before the vine. Eventually, he made his way to the Central Coast and became a vineyard manager for Horizon Vineyard Management where he also farmed for ARCH. With ARCH, Lawrence found immediate success managing wine grapes in the Edna Valley because he implemented several common table-grape farming practices, including leaf thinning, that were new to the Central Coast viticulture industry. Lawrence and $\mathrm{ARCH}$ were also responsible for planting a significant portion of the initial vine acreage in the Edna Valley.

Lawrence remembered 1997 as a major turning point in his career with respect to farming practices used in the Central Coast wine industry. There was a big movement toward organic farming, but given the environmental pressures at certain sites, the amount of fungicides, although organic, was steadily increasing and the number of passes through the vineyard with crews and tractors was higher than would have been required from a conventional approach to viticulture. There were also a number of new homes being built in the middle of vineyard blocks, and Lawrence was trying to balance the health of the homeowners with the necessary spray schedules. He wanted to make sure that agriculture could exist harmoniously with the community and the vineyard maintenance crews. As he had many times before, he reflected on what was best for the workers and the environment. He concluded that perhaps a modernized approach to conventional farming - a sustainable approach — could be the best approach to tackle the many challenges facing the emerging Central Coast wine industry. With that and the changes implemented by Joelle, farming practices at $\mathrm{ARCH}$ were evolving and leading the way for the local industry.

It would be several years before the $\mathrm{ARCH}$ team would bring on researchers to formally investigate the impact of environmentally sensitive farming practice. Specifically, knowledge of the vineyard soil microbial diversity and population abundance was perhaps necessary to reconcile the increased farming management costs. Joelle, Miles, and Lawrence knew their responsibility would always be to the environment first, but they wanted to have a better grasp of the financial ramifications and the long-term marketability of their fruit and wine. Lawrence felt strongly that wine made from SIP Certified fruit would not demand a higher price per bottle, but more of it could be sold. In other words, although consumers might not pay more for a bottle, they would select a sustainably produced bottle of wine over that of non-certified competitors. Lawrence summed it up by saying:

Organic has its place, but it isn't every single vineyard site. Considering oneself sustainable over organic is, in fact, more sustainable. Sustainable practices are focused on a site-by-site approach. Organic is a rigid and legally controlled system and it is not sustainable in the Edna Valley. Period. This is partially due to fungal pressures and cooler climates this region is subjected to. Sustainable viticulture is sustainable. We want to 
document what is actually changing in the soil environment. Block 001 is the perfect place to explore this approach.18

\section{LOOKING AHEAD}

Joelle knew the pros and cons of making the transition to sustainability permanent in Block 001. She had the soil microbial data in hand; she tasted the wines from the experimental lots; and, she discussed the importance of sustainable practices with the winemaking team, the Vineyard Team organization, and industry peers. She also knew that a sustainable approach should be adjusted on a site-by-site basis as Lawrence advocated. She was well aware of the importance of the SIP Certification to consumers. However, she was questioning the decision on some of the specific sustainable practices being tested, especially because of her concern over increased tractor passes through the block, increased personnel time, and the lack of clear impact on the wines. Still, her vineyard management team and her supervisor, Lawrence Larsen, were confident in moving forward with making Block 001 as sustainable as possible. The question was were these commonly sustainable practices truly sustainable at this site? Joelle knew that some of the management costs of the block would dissipate when the researchers were done conducting experiments. The entire vineyard block could move toward being farmed in a homogeneous manner. Although Joelle and Miles knew that the wine consumer favored sustainably farmed wines and might be willing to pay a premium for it, they feared ARCH's reluctance to increase bottle price and that they would have to consider the risk to continue investing in such an expensive practice. It would take years to examine the true cost benefit in farming sustainably and there was no way for ARCH to gauge consumer willingness to buy a SIP Certified product. At the end of the day, she and Miles were concerned with the confusion surrounding industry terms and how to appropriately market ARCH's farming efforts among the wine customers. 


\section{Appendix \\ Vineyard Data}

One of the reasons Miles initiated the work with the California State University research team was to help classify the benefits to sustainable farming that are less understood. In 2015 the research team began to work with $\mathrm{ARCH}$. The aim of the experiment was to assess how the conventional and sustainable viticulture practices affected not only vine health and wine quality, but also the soil characteristics and the diversity of soil microorganisms. Block 001 was divided into sections that were farmed with the methods, representing either conventional or sustainable approaches. The experiment examined the use of herbicides versus the sustainable manual Clemens weed knife cultivation for weed control. Treatments were applied at the beginning and throughout the 2016, 2017, and 2018 growing seasons.

Data were collected on vines, berries, and soil at four points throughout the growing season, including bloom, budbreak, vérasion, and harvest. Soil samples were collected from under vine rows where the treatments were applied, in multiple sections for each treatment. The soil microbial communities were identified in a way that determined which microorganisms were present, and in what relative abundance they were present.

\section{Exhibit A}

\section{Soil Microbial Diversity Index of Herbicide (HERB) and Cultivated (NH) Areas}

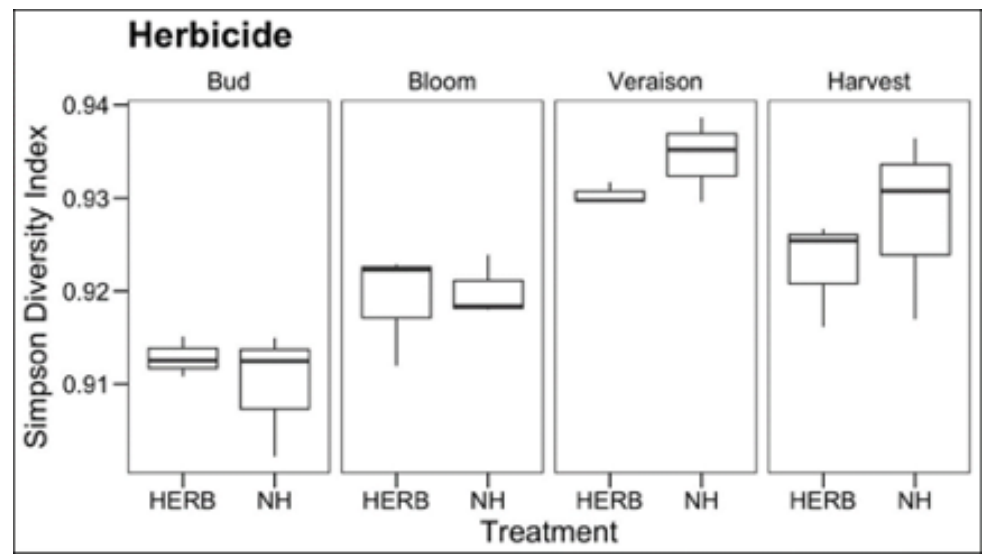

Source: California Polytechnic State University Research Team for ARCH.

Data reflects Findings from 2016 with respect to Microbial Diversity as Function of Time.

The research team reduced the data from each soil sample into a single measure of diversity known as the Simpson Diversity Index (SDI). The closer the value of the SDI to one, the higher the diversity. Exhibit A displays an example of the change in diversity of bacteria in soil over the growing seasons and compares an herbicide treatment with a control (not treated with 
herbicide). It was determined that bacterial diversity increased throughout the growing season, especially during vérasion and harvest. Additionally, the sustainable treatment that lacked herbicide had higher diversity.

Healthy soil contained the appropriate nutrients in sufficient quantities, and there was increasing evidence that microbial communities in soil play a vital role in maintaining nutrient balance. 19 Of particular importance are the organisms that produce or release nutrients that would become bioavailable for plants. The long-term benefit of understanding the composition of soil microbial communities and their function in a specific soil system could allow viticulturists to reduce the use of chemical fertilizers and to adopt more sustainable practices in vineyard management. 


\section{Endnotes}

1 American Viticultural Area (AVA) refers to a specific area in the U.S. that is federally recognized, where grapes were grown and sourced. The designation of an AVA is done to enable both industry and consumers to attribute specific quality or sensory characteristics of a wine from grapes grown in a certain geographic region. AVA designation is regulated by the Alcohol and Tobacco Tax and Trade Bureau (TTB). For a wine to be labeled with a specific AVA, a minimum of $85 \%$ of the grapes that went into the wine must have been grown within that AVA.

2 At the core of this case, there is a need to clarify terms that sound generic, lack clarity, or may have varying definitions among industry professionals. Several industry organizations have emerged to bring transparency to this complicated issue. Joelle Ainsley and the ARCH vineyard team had been committed to sustainable farming, becoming SIP certified in 2006. Sustainability in Practice is broadly defined as:

Sustainability in Practice Certification helps farmers and winemakers demonstrate their dedication to preserving and protecting natural and human resources. Sustainability in Practice Certified is a rigorous sustainable vineyard and winery certification with strict, non-negotiable requirements, committed to standards based on science and expert input, independent verification, transparency, and absence of conflict of interest.

The authors in this case have decided to use the designations sustainable and environmentally friendly to define farming techniques and concepts under scrutiny by Joelle Ainsley and the wine-grape farming community and under the guidance of SIP certified farming practices.

3 Wines Vine Analytics. (n.d.). Retrieved July, 2018, from

https://www.winesandvines.com/template.cfm?section=widc\&widcDomain=wineries\&widcYYYYMM=201807

4 Pellechia, T. (2017, February 01). The U.S. Wine Industry Focuses On A Sustainable Future. Retrieved from https://www.forbes.com/sites/thomaspellechia/2017/02/01/the-u-s-wine-industry-focuses-on-a-sustainable-future/

52014 Cone Communications Food Issues Trend Tracker PDF - Cone Communications | Cone | Cone PR | Cone Inc | PR Agency | Boston | NYC. (2014). Retrieved from http://www.conecomm.com/2014-cone-communications-foodissues-trend-tracker-pdf/

6 McMillan, R. (2018). State of the Wine Industry 2018 (Rep.). Retrieved from

https://www.svb.com;globalassets/library/images/svb-2018-wine-report.pdf

7 Wine Market Council. (2018, April 19). Wine Market Council Releases Results of "Green" Study Highlighting U.S. Wine Consumer Attitudes Toward Organic, Sustainable and Biodynamic Production [Press release]. Retrieved from https://www.winebusiness.com/news/?go=getArticle\&dataid=198041

8 Mobley, E. (2018, June 22). California wine's sustainability dilemma. SF Chronicle. Retrieved from https://www.sfchronicle.com/wine/article/California-wine-s-sustainability-dilemma-13018068.php

9 The Vineyard Team is an organization designed to education and guide grape growers towards sustainable winegrowing practices. Available at: http://www.vineyardteam.org/

10 Integrated Pest Management (IPM) is a step-by-step procedure used to address pest problems while simultaneously minimizing risks to the environment and people. This approach is supported and continually under development and review at the University of California. Available at: http://ipm.ucanr.edu/ 
11 USDA Organic is a legally recognized certification for agricultural products. The National Organic Program (NOP) develops the rules and regulations that govern organic production, handling, labeling and enforcement for all of the USDA organic products. Available at: https://www.usda.gov/topics/organic

12 Kris Beal [Personal interview]. 2018.

13 Joelle Ainsley [Personal interview]. 2018.

14 A California Pest Control Advisor is licensed by the Environmental Protection Agency to specialize in the management of pests, generally in an agricultural setting. Available at: https://capca.com/pca/

15 Miles Owens [Personal interview]. 2018.

16 Sustainability in Practice (SIP) Certification is issued by the SIP organization when a vineyard or a winery meets a set threshold for certain environmental and human resource protections. The certification process is carried out by independent verification and third-party inspections. Available at: http://www.sipcertified.org/

17 McMillan, R. (2018). State of the Wine Industry 2018 (Rep.). Retrieved from

https://www.svb.com;globalassets/library/images/svb-2018-wine-report.pdf

18 Lawrence Larsen [Personal interview]. 2018.

19 Lee, J., \& Steenwerth, K. (2013). 'Cabernet Sauvignon' grape anthocyanin increased by soil conservation practice. Scientia Horticulturae. 159, 128-133. 